Original Research Paper

\title{
Geometrical morphology characterization and taxa identification of land Snail populationsin Algeria
}

\author{
Bouchiba I. Metahri R. Ameur Ameur A. Gaouar S. B. S. \\ Laboratory Pathophysiology and Biochemistry of Nutrition (PpBioNut), Department of Biology, Faculty of \\ Nature and Life Sciences, University of Tlemcen. \\ ${ }^{2}$ Department of Agronomic, University of Tlemcen, Algeria
}

Corresponding Author: Dr. AMEUR AMEUR. Abdelkader, Universityof Tlecmen. Email: ameurabdelkader@gmail.com.

\begin{abstract}
In the context of the evaluation of animal genetic resources in general and the diversity of land snails in particular, we contributed to a morphometric and phenotypic study of this animal groupes 14 districts whose, they are recognized by their snail production. To achieve the objective measurements with geometrical approaches were collected from 751 individuals. Four parameters related to the body of each animal as the height of the shell (HC), the length of shells (LC),shell width (LGC) and the weight (P) and two phenotypic characters flesh color (CCH) and shell color (CC). The ANOVA test show a significant differences on body measurements between districts andspecies. In fact, the obtained results show that the Otala punctate is the most common species in Algeria; otherwise, there is significant phenotype variability betweenindividuals, which confirms that snails exhibit a large polymorphism. An Independence test was carried out on the phenotypic characteristics revealing that the regions influence the qualitative characteristics.This study it one of very few research undertaken in this field especially in Algeria. It is an important approach to be taken into consideration during conservation and improvement programs for this endangered species because of illegalpickup. Keywords: Land Snail, Characterization, Measurement, Phenotype, Algeria
\end{abstract}

\section{Introduction}

To humans, the snail is an ambivalent animal, both rejected and familiar. It is also a paradoxical organism, which frequently compensates for its proverbial slowness with a formidable passive dispersion (Frédéric and Sophie, 2012). Throughout the Mediterranean basin and according to the results obtained by (LabuaneandMagnin, 2001)that habitat and structureof the land snailspopulation area more important explanatory factor than floristic composition. There analyses emphasize the important role played by nonenvironmental factors (particularly historic factors)expressed by independent spatial variables. Nevertheless, it is difficult to discriminate between the influenceof climatic factors, historic events and/or bioticfactors within the altitudinal gradient.

The snail is a gastropod mollusk who feeds mainly on plants; snails are hermaphrodites, but these animals reproduce by mating (self-fertilization is impossible). There are 400 species of which the most countered species is Helix aspersa, the latter is an excellent bioindicator of more effective land pollution than the earthworm Lumbricusterrestris (Gomot-de Vaufleury and Pihan, 2000). Due to its sedentary lifestyle on soils and its herbivorous diet, it is easily contaminated by the various pollutants present in the air, soil and flora, hence the interest of its use as a test organism to study the influence of metallic trace elements on its growth (Cortet et al., 1999)

Heliciculture is an activity that promotes short circuits with sales from producer to consumer, and which helps to develop a rural and local economy. Snail slime is considered today to be a true wonder of nature; it is revolutionizing the world of cosmetics and skin care products; as a direct consequence the price of slime is on the rise on the market (de Vaufleury et al., 2009)

In Algeria despite its remarkable diversity of snail species and the high demand for its consumption in some regions, unfortunately, there are few studies on breeding and phenotypic characterization for these local populations of land snails except some on biosystematics (Damerdji, 1990) and ecological as bioindicators of soil pollution (Zaafour, 2014). 
In this context, and in order to improve the situation of Algeria in heliciculture. This study, as the first of its kind, came to identify and characterize the local populations of land snails over the entire Algerian territory, using morphometric and phenotypic approaches. This steppe is very important to know the potential resource in Algerian snails for a good plan to preserve and to exploit economically.

\section{Materials and methods}

\section{Animal material}

The animal material of the study consisted of a total of 751 animals from 14 districts in different locations in Algeria (Figure 1). The sample sizes of snails' population studied are presented in Table 1 in which 33 regions are visited with a total area equal to $79,607 \mathrm{~km}^{2}$.In fact, the sampling was done according to two different procedures, either by direct collection of the animal in its natural habitat and by purchases in local markets in all the regions visited (Figure 2). These regions targeted for this study have temperatures and rainfall that differ from one district to another in order to permit us having a maximum chance to identify all local populations of land snails in Algeria.

Table 1. Origin and sample size of all snail population sampling

\begin{tabular}{lll}
\hline District & Regions of sampling & Sample \\
\hline Saida & Ain El Hadjar, Hounet & $\mathbf{3 5}$ \\
Mila & Beni Haroun & $\mathbf{3 2}$ \\
El Tarf & El Kala & $\mathbf{7 4}$ \\
Constantine & Djebel El Ouahch & $\mathbf{7 3}$ \\
Annaba & Cheurfa & $\mathbf{3 2}$ \\
Setif & Béni Aziz & $\mathbf{5 2}$ \\
Tlemcen & Ouiziden, Maghnia, Ain youcef, Ain fezza,Hennaya, Gouassir, Ghazaouat El Fhoul & $\mathbf{1 8 0}$ \\
Oran & Bethioua, Misserghin & $\mathbf{3 3}$ \\
Sidibelabbes & Hassi Zehana, Lamtar & $\mathbf{3 5}$ \\
Mostaganem & Ain tédlès & $\mathbf{4 0}$ \\
Ain Témouchent & Ain kihal, Chaabat ElLeham, Sidi Ben Adda Ain El Arbaa & $\mathbf{3 1}$ \\
Naama & AinSefra, Tighennif & $\mathbf{3 3}$ \\
Mascara & Maoussa & $\mathbf{3 1}$ \\
Alger & Ain benian, Bouchaoui, Bainem, Ben Aknoun & $\mathbf{7 0}$ \\
\hline Total & & $\mathbf{7 5 1}$ \\
\hline
\end{tabular}

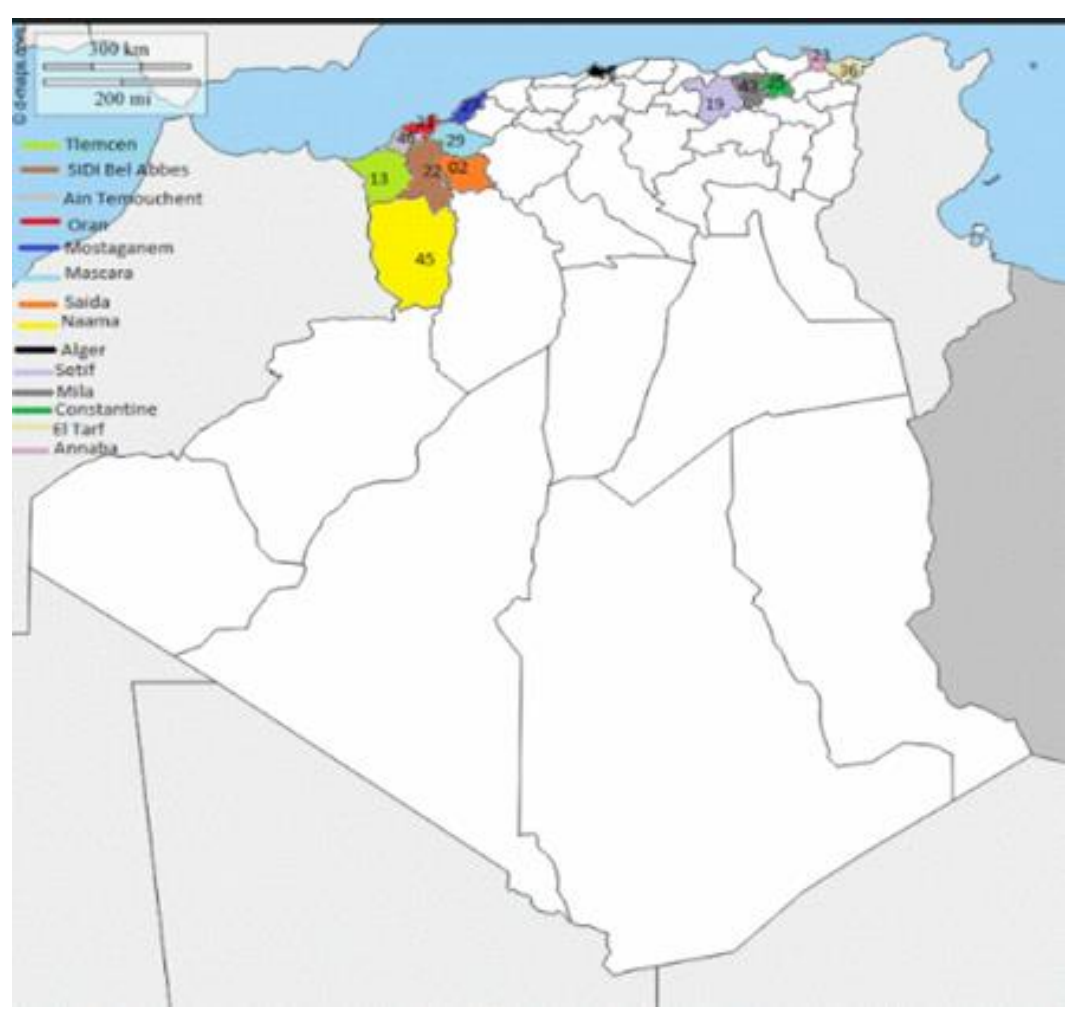

Figure 1. Sampling districts. 


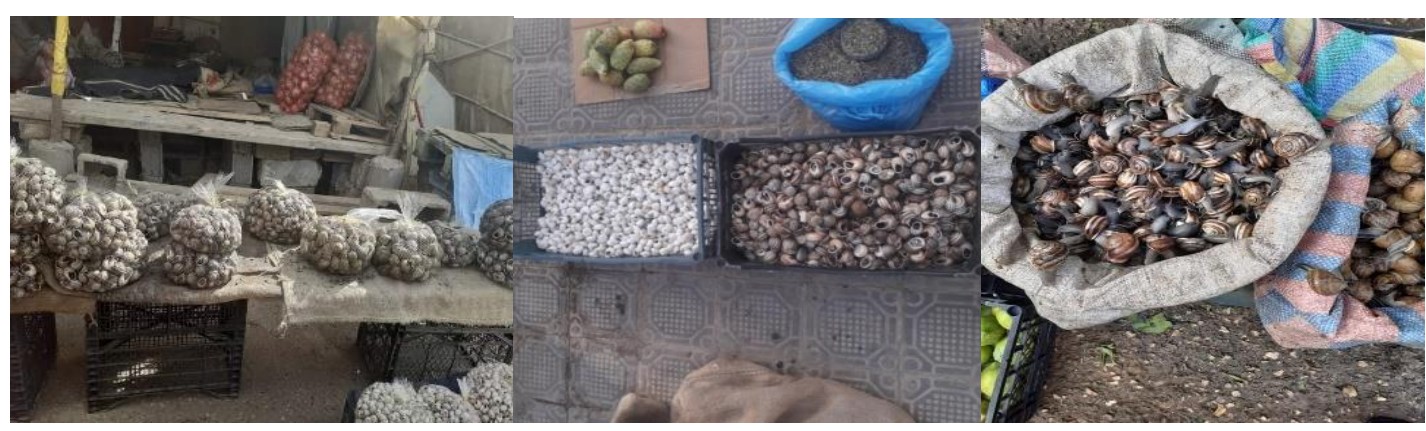

Figure 2. Some local snail markets in Algeria

\section{Species identification}

The identification was carried out with the following criteria:

- The shape, size, color, turns of the shells are all useful elements in determining and identifying snail species.

- The general shape of the shell is determined by the shape of the towers and their mode of growth. The turn can be very low and be located below the upper edge of the last turn; it can be plastered or elongated and take very different shapes in the case of convex shells, it can be conical convex, more or less cylindrical or spindle-shaped until close to the apex.

- The size of the shell is also an important characteristic. Two main dimensions, diameter and height, are decisive for the description.

- The characteristics of the opening of its margin, the peristome, are often decisive for identification, but are clearly manifested only in adults.

- The typeface has other characters useful for identification. In some species, it may be hairy; the hairs are an extension of the periostracum. They are frequently absent; due to abrasion of aged shells, but their insertion, points remain visible at high magnification.

- Shell color and thickness vary greatly from species to species. These characters are the ostracum; the thinner and less calcified it is, the more translucent the shell.

- The shells of some species turn milky white after the animal's death. The shell may have bands, spots of different shades, and sometimes the peristome itself has its own coloring.

\section{Morphological traits studies}

About the quantitative characters, the measurements were processed by Image $\mathbf{J}$ software analysis with a 32bit platform (Rasband 2014) after having photographed each individual from several angles and then entered the image in software to calculate the following measurements (figure $3 \mathrm{~A}$ and $\mathrm{B}$ ): The height of the shell (HC), the length of shell (LC) and shell width (LGC). The weight (P) parameter was measured using an electronic scale. In regards to the qualitative traits, two characters were taken into consideration which dominates the phenotype and which are: flesh color $(\mathrm{CCH})$ and shell color $(\mathrm{CC})$

\begin{tabular}{ll|l}
\hline A & B \\
\hline & &
\end{tabular}

Figure 3. A: Measurement of weight B: Measurement of length, width and height of the shell 


\section{Statistical analysis}

Statistical analysis tests were performed by SPSS software version 21.0 in order to group together individuals who carry the same characteristics studied based on body measurements to define a classification and present the qualitative characteristics. In order to estimate the phenotypic diversity of quantitative traits, the Shannon-Weaver index (Shannon and Weaver, 1964) is calculated based on the frequencies of the classes corresponding to each trait. The Shannon-Weaver index is given by the following formula:

Pi: frequency of class $i$

$\mathrm{n}$ : number of individuals of a class in the sample

A value of the relative diversity index $(\mathrm{J})$ is obtained

$$
H=-\sum_{i=1}^{n} \mathrm{Pi} \operatorname{Ln} \mathrm{Pi}
$$

The Shannon and Weaver index was obtained by $\mathrm{R}$ software version 3.5.2

\section{Results}

According to our surveys, the district of El Tarf presents more species variability compared to other districts (Helix pomatia, helix aspersa, pseudotacheasplendida, Gllandiaannularis, cryptomphallusaspersus, Cepeahortensis, Cepeanemoralis, Helicellaitemorala, Cepeasylvatica) The rest of the districts have few varieties such as Constantine (Helix aspersa, Ariantaarbustrum, Helix pomatia), Algiers (Otalapunctata, Thebapisana), Tlemcen (Thebapisana, Helix pomatia, Pseudotacheasplendida, Otalapunctata), Mila, Annaba and Setif (Helix aperta), Oran, Sidi Bel Abbès, Ain Témouchent, Saida, Mostaganem, Mascara (Otalapunctata) and Naama (Sphincterochilaboissieri).

\section{Species Identification}

Figure 4 shows the set of 15 species of land snail have been identified, which shows very high phenotypicdiversity of the shell of this taxa in Algeria.

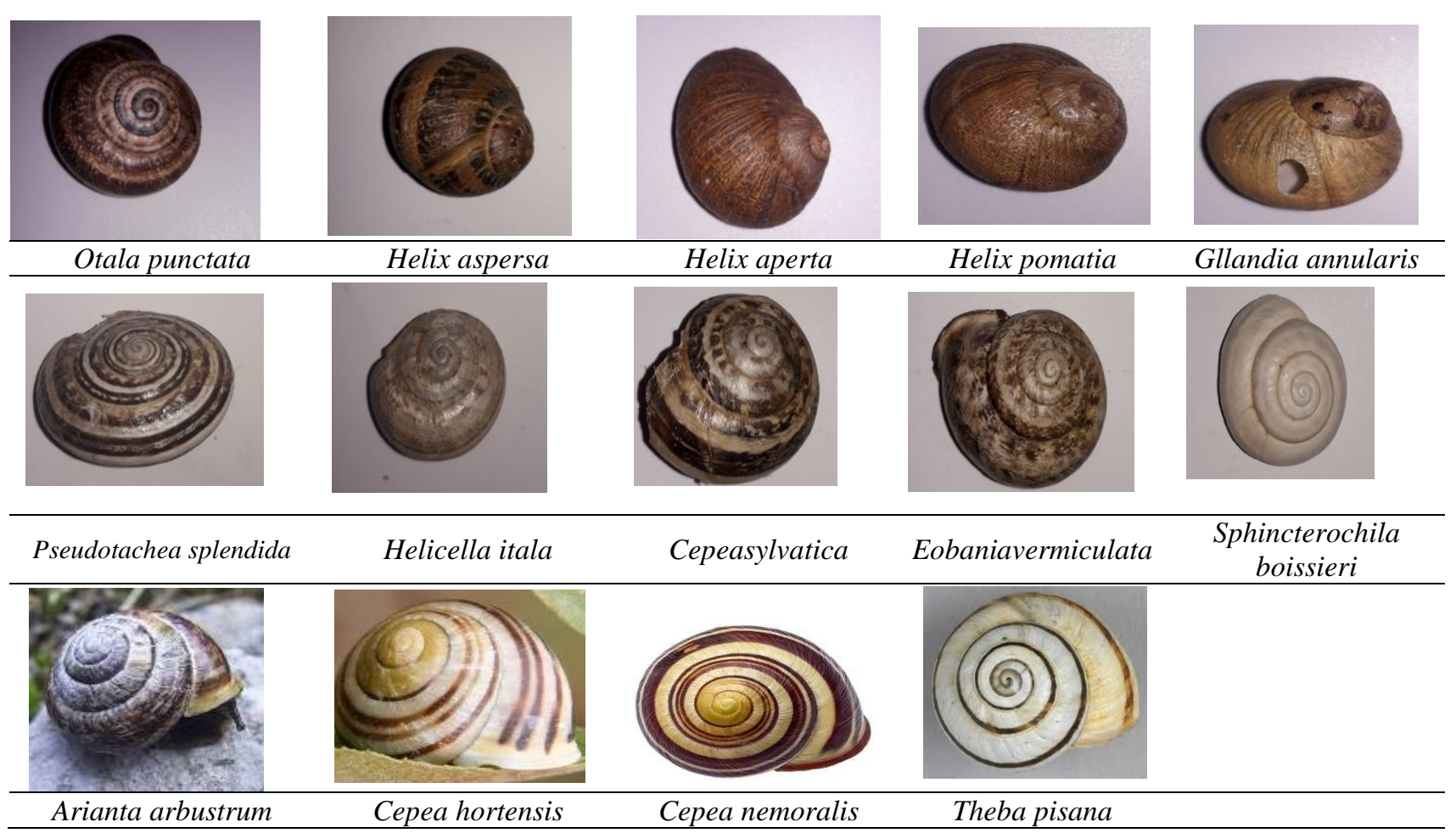

Figure 4. 15 Land snailsspeciesidentified in the Algerian territory.

\section{Ecological Shannon and Weaver index}

The Shannon-Weaver index is the most commonly used and is recommended by various authors (Gray et al, 1992). The Shannon index is used to express diversity by taking into account the number of species and the abundance of individuals within each of these species(Grall and Coïc, 2006). 
This index is relatively average for the 14 districts studied, which is probably a reflection of very significant genetic diversity with an overall rate, which is equal to 1.37. The value of the index increases with the degree of polymorphism and reaches a maximum value when all the phenotypic classes have equal frequencies. In fact, the populations of Mila, Naama, Saida, Bel Abbès, Ain Témouchent, Mascara, and Oran are almost identical. Therefore, the snail population studied is very polymorphic; Annaba (0.73), Constantine (1.28), Tlemcen (1.88), El Tarf (1.15), Mila (0.48), Setif (0.9), Naama (0.47), Mostaganem (0.52), Algiers (0.92), Saida (0.49), Sidi Bel Abbès (0.49), Ain Témouchent (0.45), Mascara (0.46) and Oran (0.46) (Table 2).

This diversity of the Shannon index may be due to several factors such as adaptation to local conditions and characteristics of exploited regions such as altitude, precipitation, vegetation and temperature.

Table 2. Shannon and Weaver diversity index

\begin{tabular}{cccc}
\hline Districts & \multicolumn{2}{c}{ Characters } & Overall mean \\
\cline { 2 - 3 } & CCH & CC & 0.73 \\
Annaba & 0.66 & 0.80 & 1.28 \\
Constantine & 0.73 & 1.11 & 1.88 \\
Tlemcen & 1.04 & 1.69 & 1.15 \\
El Tarf & 0.96 & 1.35 & 0.48 \\
Mila & 0.46 & 0.50 & 0.9 \\
Setif & 0.60 & 0.60 & 0.47 \\
Naama & 0.47 & 0.47 & 0.52 \\
Mostaganem & 0.52 & 0.52 & 0.92 \\
Alger & 0.92 & 0.92 & 0.49 \\
Saida & 0.49 & 0.49 & 0.49 \\
Sidi-Bel Abbès & 0.49 & 0.49 & 0.45 \\
AinTémouchent & 0.45 & 0.45 & 0.46 \\
Mascara & 0.46 & 0.46 & 0.47 \\
Oran & 0.47 & 0.70 & $\mathbf{1 . 3 7}$
\end{tabular}

Flesh color $(\mathrm{CCH})$ and shell color $(\mathrm{CC})$

Quantitative traits

Table 3. Variation in shell height $(\mathrm{cm})$, length $(\mathrm{cm})$ and width $(\mathrm{cm})$ and body weight $(\mathrm{g})$ depending on the species

\begin{tabular}{|c|c|c|c|c|c|c|}
\hline \multirow[t]{2}{*}{ Species } & $\mathbf{N}$ & Weight(g) & $\mathrm{HC}(\mathrm{cm})$ & $\mathrm{LC}(\mathrm{cm})$ & LGC (cm) & \multirow[t]{2}{*}{ Sig. } \\
\hline & \multicolumn{5}{|c|}{ Mean \pm SE } & \\
\hline Helix aperta & 116 & $4.33 \pm 1.60$ & $1.56 \pm 0.27$ & $2.46 \pm 0.32$ & $1.94 \pm 0.53$ & $* * *$ \\
\hline Helix pomatia & 55 & $9.34 \pm 3.46$ & $2.47 \pm 0.91$ & $3.52 \pm 0.86$ & $2.61 \pm 0.56$ & $* * *$ \\
\hline Helix aspersa & 51 & $7.07 \pm 2.69$ & $1.89 \pm 0.40$ & $2.76 \pm 0.56$ & $2.19 \pm 0.50$ & $* * *$ \\
\hline Ariantaarbustrum & 10 & $7.40 \pm 2.63$ & $1.73 \pm 0.24$ & $2.68 \pm 0.37$ & $1.95 \pm 0.24$ & $* * *$ \\
\hline Otalapunctata & 292 & $10.37 \pm 3.11$ & $2.13 \pm 0.40$ & $4.25 \pm 0.45$ & $3.34 \pm 0.31$ & $* * *$ \\
\hline Thebapisana & 109 & $3.99 \pm 1.10$ & $1.75 \pm 0.57$ & $2.60 \pm 0.52$ & $2.16 \pm 0.41$ & $* * *$ \\
\hline Pseudotachiasplendida & 35 & $5.56 \pm 2.69$ & $1.67 \pm 0.32$ & $2.72 \pm 0.33$ & $2.28 \pm 0.25$ & $* * *$ \\
\hline Helicellaitala & 16 & $2.35 \pm 0.25$ & $1.57 \pm 0.27$ & $2.35 \pm 0.15$ & $2.14 \pm 0.27$ & $* * *$ \\
\hline Eobaniavermiculata & 3 & $3.26 \pm 0.15$ & $1.88 \pm 0.11$ & $2.95 \pm 0.32$ & $2.68 \pm 0.16$ & $* * *$ \\
\hline Cepeasylvatica & 4 & $2.12 \pm 0.09$ & $1.49 \pm 0.09$ & $2.32 \pm 0.04$ & $2.12 \pm 0.15$ & $* * *$ \\
\hline Cryptomphalusaspersus & 17 & $5.58 \pm 2.29$ & $2.85 \pm 0.33$ & $3.41 \pm 0.39$ & $2.90 \pm 0.31$ & $* * *$ \\
\hline Gllandiaannularis & 8 & $5.37 \pm 3.99$ & $3.02 \pm 0.62$ & $3.59 \pm 0.86$ & $2.88 \pm 0.46$ & $* * *$ \\
\hline Sphincterochilaboissieri & 33 & $5.57 \pm 1.52$ & $2.33 \pm 0.36$ & $2.85 \pm 0.11$ & $2.50 \pm 0.59$ & $* * *$ \\
\hline Overall mean & 751 & $7.34 \pm 3.82$ & $1.99 \pm 0.56$ & $3.35 \pm 0.93$ & $2.67 \pm 0.68$ & \\
\hline
\end{tabular}

Height of the shell (HC), Length of shells $(L C)$ and shell width $(L G C)$ : ***:p<.001. Sig: significate

The body measurements studied in each species of the land snail population arepresented in Table (3). There is a very significant difference $(\mathrm{p}<0.05)$ between the 15 species studied on all the morphological characters. In fact, we found a remarkable variation in the weight of the land snail between the 15 species studied. We have found a small species such as Cepeasylvatica and Helicellaitala, with a weight that does not exceed 2.5g. On the other hand, Otalapunctata and Helix pomatia are relatively heavy species with a weight around $10 \mathrm{~g}$. The rest of the species have average weights that are sometimes similar.However, the morphology of the shell shows a very homogeneous variation between these species except Otalapunctatashows much greater measurements compared to other species, which explains its developed weight.Hence, the High 
Length and widthof the shell presents a highly significant difference between the studied species ( $\mathrm{P}$ value $<0.05)$, as it is indicated in table 3 .

In the 14 districts studied an average general weight of $7.34 \mathrm{~g}$ was recorded with a minimum weight of 3.77 $\pm 1.13 \mathrm{~g}$ and maximum of $12.34 \pm 1.58 \mathrm{~g}$ in the districts of Sétif and Sidi bel abbes respectively, this can be explained by the presence of more heavy snail populations (Otalapunctata) in the Sidi Bel Abbes district than other lighter populations (Helix aperta) in the El-Taref district (Table 4).

With regard to the dimensions (height, width and length) of the carcass of the land snail in Algeria, the results obtained between the regions studied show respective means $1.99 \pm 0.56 \mathrm{~cm}, 3.35 \pm 0.93 \mathrm{~cm}$ and 2.67 $\pm 0.68 \mathrm{~cm}$ respectively. In general, the shape of the carcass of local snail populations presents a certain morphological homogeneity may be due to the common origin of these populations and to environmental conditions. However, ANOVA analysis shows a significant difference of all the morphological characters studied between the individuals of the snail populations according to the region. Furthermore, the principal component analysis (PCA) shows that the two axes 1 and 2 respectively represent $75.29 \%$ and $92.119 \%$ of the total inertia, the characters are subdivided in two groups of variables. Axis 1 (75.29) is represented by LC, LGC while Axis 2 (92.11) is represented by P, HC (figure 4). In fact, all characters are correlated positively.

Table 4. Variation in shell height, length and width and body weight depending to the district.

\begin{tabular}{ccccccc}
\hline District & $\mathbf{N}$ & Weight $(\mathbf{g})$ & HC $(\mathbf{c m})$ & LC $(\mathbf{c m})$ & LGC $(\mathbf{c m})$ & Sig \\
\cline { 3 - 6 } & & \multicolumn{4}{c}{ Mean \pm SE } \\
\hline Annaba & 32 & $5.06 \pm 1.85$ & $1.21 \pm 0.14$ & $2.12 \pm 0.26$ & $1.60 \pm 0.19$ & $* * *$ \\
Constantine & 73 & $7.50 \pm 2.21$ & $1.75 \pm 0.26$ & $2.69 \pm 0.34$ & $2.06 \pm 0.27$ & $* * *$ \\
Tlemcen & 180 & $6.78 \pm 3.56$ & $2.14 \pm 0.70$ & $3.30 \pm 0.76$ & $2.59 \pm 0.52$ & $* * *$ \\
EL tarf & 74 & $4.27 \pm 3.08$ & $2.24 \pm 0.67$ & $2.94 \pm 0.76$ & $2.56 \pm 0.56$ & $* * *$ \\
Milla & 32 & $4.68 \pm 1.61$ & $1.74 \pm 0.21$ & $2.39 \pm 0.21$ & $1.78 \pm 0.19$ & $* * *$ \\
Setif & 52 & $3.77 \pm 1.13$ & $1.67 \pm 1.67$ & $2.70 \pm 0.17$ & $2.25 \pm 0.22$ & $* * *$ \\
Naama & 33 & $5.57 \pm 1.52$ & $2.33 \pm 0.36$ & $2.85 \pm 0.11$ & $2.50 \pm 0.05$ & $* * *$ \\
Mostaganem & 40 & $6.15 \pm 2.40$ & $2.37 \pm 0.32$ & $4.34 \pm 0.36$ & $3.18 \pm 0.15$ & $* * *$ \\
Alger & 70 & $8.02 \pm 4.20$ & $1.86 \pm 0.78$ & $3.46 \pm 1.19$ & $2.76 \pm 0.84$ & $* * *$ \\
Saida & 35 & $12.05 \pm 0.99$ & $2.08 \pm 0.19$ & $4.31 \pm 0.43$ & $3.44 \pm 0.19$ & $* * *$ \\
Sidi Bel Abbès & 35 & $12.34 \pm 1.58$ & $2.09 \pm 0.22$ & $4.55 \pm 0.25$ & $3.52 \pm 0.20$ & $* * *$ \\
Ain temouchent & 31 & $11.29 \pm 2.47$ & $1.95 \pm 0.25$ & $4.06 \pm 0.49$ & $3.39 \pm 0.24$ & $* * *$ \\
Mascara & 31 & $11.38 \pm 2.24$ & $1.97 \pm 0.22$ & $4.30 \pm 0.38$ & $3.42 \pm 0.24$ & $* * *$ \\
Oran & 33 & $11.42 \pm 2.37$ & $2.01 \pm 0.23$ & $4.46 \pm 0.32$ & $3.42 \pm 0.23$ & $* * *$ \\
\hline Overall mean & 751 & $7.34 \pm 3.82$ & $1.99 \pm 0.56$ & $3.35 \pm 0.93$ & $2.67 \pm 0.68$
\end{tabular}

Height of the shell (HC), Length of shell (LC) and shell width (LGC): ***:p<.001.

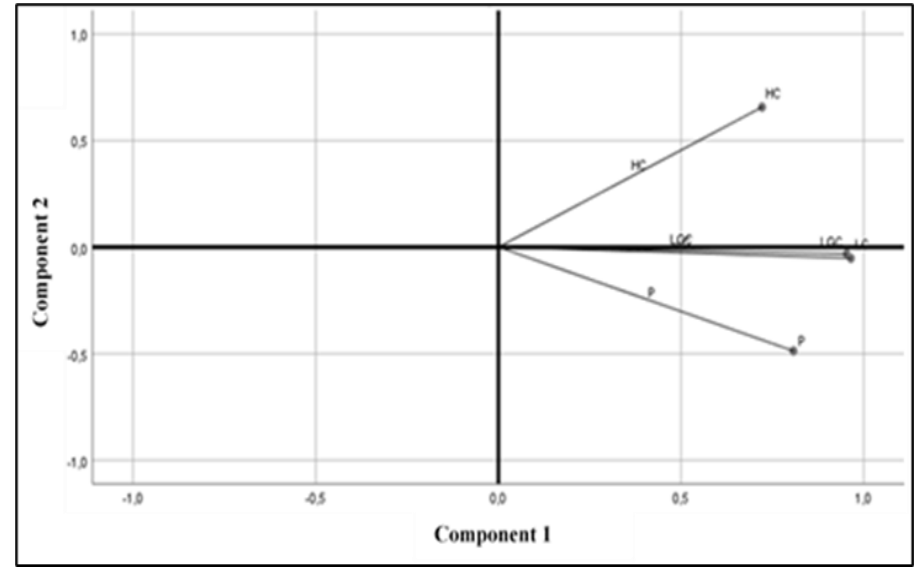

Figure 5. presentation of body measurements by PCA in the snail population Height of the shell (HC), Length of shells (LC) and shell width (LGC): ***:p<.001

Based on the results of the PCA (Figure 5) two different classes of snails are determined. (Table 5, Figure 6). 
Class01: this class is in the majority, it presents more than half of the population studied (563); snails of this class have the shortest shells $(1.92 \pm 0.57) \mathrm{cm}$ and less long $(3.02 \pm 0.79) \mathrm{cm}$ with a narrow width $(2.42 \pm$ $0.58) \mathrm{cm}$ as well as a less massive weight $(5.53 \pm 2.39) \mathrm{g}$.

Table 5. Description of two class of land snails by ACP

\begin{tabular}{lll}
\hline & Classe 01 & Classe 02 \\
\hline $\mathbf{N}$ & 563 & 188 \\
$\mathbf{L H}$ & $1.92 \pm 0.57$ & $2.22 \pm 0.50$ \\
$\mathbf{L C}$ & $3.02 \pm 0.79$ & $4.37 \pm 0.47$ \\
$\mathbf{L G C}$ & $2.42 \pm 0.58$ & $3.43 \pm 0.32$ \\
$\mathbf{P}$ & $5.53 \pm 2.39$ & $12.79 \pm 1.25$ \\
\hline
\end{tabular}

Class 02: snails of this class (188) are taller $(2.22 \pm 0.50) \mathrm{cm}$ with a longer shell $(4.37 \pm 0.47) \mathrm{cm}$ and wider $(3.43 \pm 0.32) \mathrm{cm}$ with more massive weight $(12.79 \pm 1.25) \mathrm{g}$

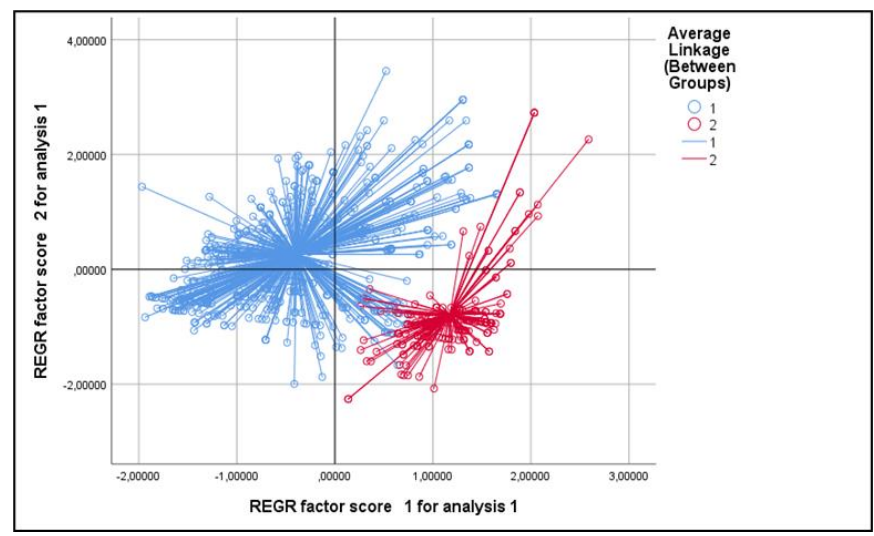

Figure 6. presentation of individuals of the snail population by PCA

\section{Qualitative traits}

The Constantine District has more color diversity (Beige and gray, gray and beige, black, black and gray) followed by Tlemcen,district (black and gray, gray, beige) then Algiers (beige, black and gray) and Annaba (black, black and gray). On the other hand, individuals from other districts have a single color Naama (beige), Sidi Bel Abbes Mascara, Mila, Oran, Saida ,Setif, Temouchent, El Tarf and Mostaganem, wear the color (black orgray) (Figure 7).

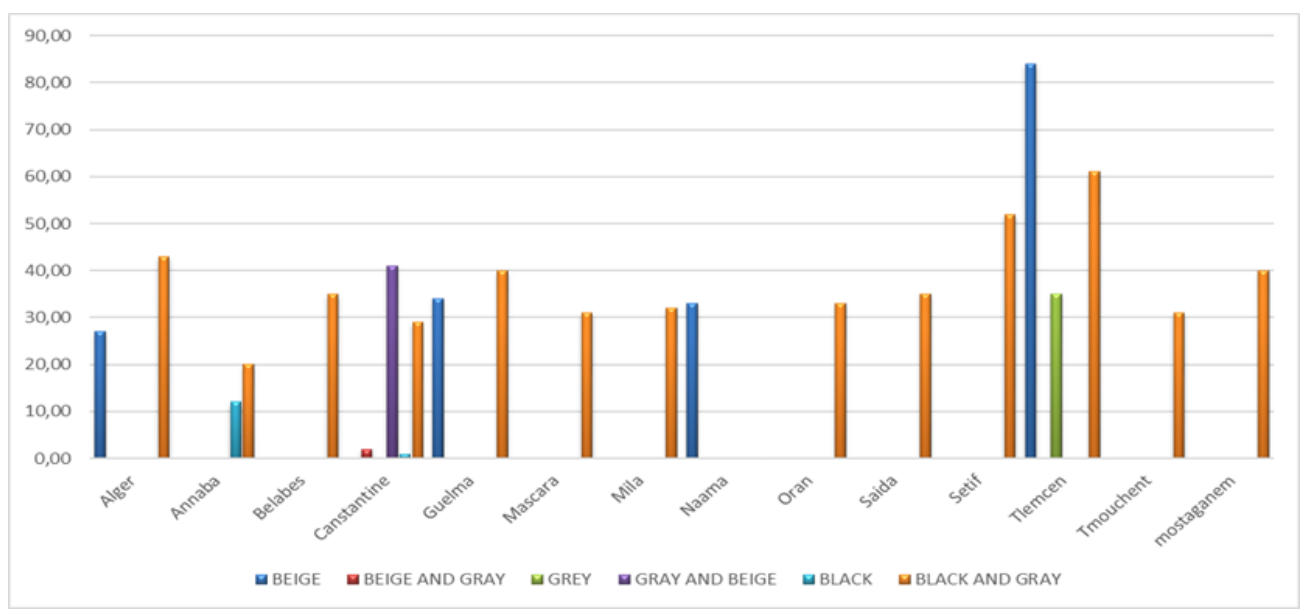

Figure 7. Diagram of the color of the flesh in the districts visited 


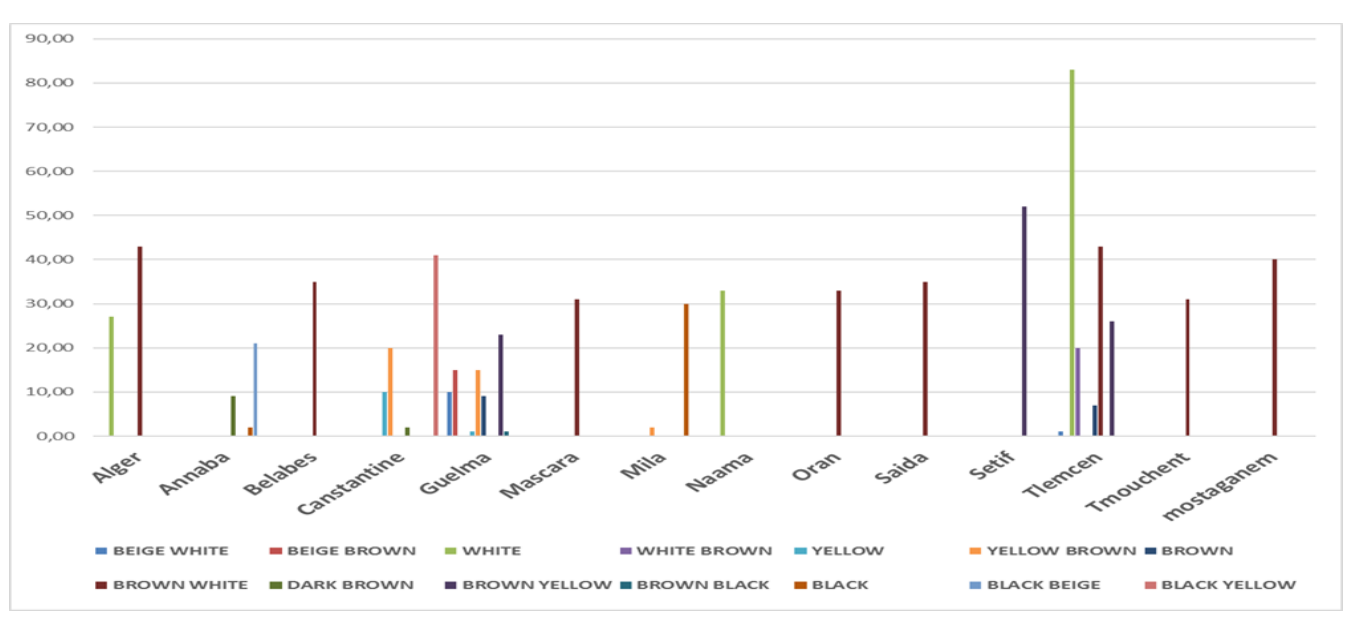

Figure 8. Shell color diagram in the districts visited.

Land Snails shell color is the mostimportant character in terms of diversity to differentiate between species.Regarding our work, the diagram above shows that the local land snail population is highly variable in terms of shell phenotype with 5 different colorsWhite, brown, yellow, black beige), either united or mixed together.In fact, the El tarf and districts has more shell color variability than the other districts with 7 and 6 shell phenotypes respectively. Then, Constantine andAnnaba with 4 colors; followed byAlgiers and Mila which includes 3 shell colors. In parallel, the other districtsare characterized by a single shell color (brown and white) like Naama;Setif, Oran, Sidi Bel Abbès, Mascara, Saida, Timouchent and Mostaganem (Figure 7)..The independence test (khi2) shows the existence of a relationship between the color of the shell and the flesh with the region studied .

\section{Discussion}

Rearing of snails is referred to as Heliciculture. It is practiced at the intensive level in United States of America, Australia and United Kingdom. Snail business is a lucrative business but over looked by many in Algeria. It only requires attention and management.This work is original in the context there is no similar study on Algerian land snail populations, so we resorted to the study of European and hedge snails.Accordingour study of variations of variables by species, the quantitative characteristics HC, LC, LGC, $\mathrm{P}$ is influenced by the species of which $(\mathrm{p}<0.05)$ so there is a highly significant difference between the shells of different species.Our study also showed the existence of significant effects of the districts on the body measurements for the parameters HC, LC, LGC P: ( $p<0.05)$.

According to the PCA, the characteristics studied are positively correlated with each other. The result obtained by a PCA of individuals (body measurements) shows that the studied population presents heterogeneity at the level of the regions explored, because we obtained two classes of individuals, the first consisting of 563 individuals of which the shells are less developed than those of the individuals of the second class, which number 188.

From the results obtained, we can interpret the heterogeneity of characters at the same species level by its individual diversity, which explains the large polymorphism of land snail populations. From the results obtained, we can interpret the heterogeneity of characters at the same species level by its individual diversity, which explains the large polymorphism of land snail populations, moreover, there is an inversely proportional relationship between altitude and temperature, so the latter means that the climate is generally different with animals and plants that are adapted do not have the same ability to adapt. Furthermore, the quality of soil can also influence the characteristics of the shell because it is part of the snail's diet and constitutes an essential calcium supply for the formation of its shell and influences its growth (Gomot et al., 1989; Dallinger et al., 2001). Regarding pollution, its impact is noted in the inhibitory effect of metal dust on the growth of snails whose long-term exposure in the laboratory tends to decrease the development of the albumen gland, the gonad and the genital tract, (Amira, 2016). From the results of the diagrams, the two qualitative traits: $\mathrm{CC}$ (shell color) and $\mathrm{CCH}$ (flesh color) differ according to species and region.

The most dominant color of the flesh; black and gray, with a shell color; brown and white.In addition, food and humidity influence the color of the flesh. Predators are also an environmental factor that plays a very 
important role in the coevolution in snails.Regarding species, each district has its own species we can say endemic. In addition, the dynamics of species are sometimes linked to that of human populations, their practices and the resulting changes in the landscape. (Frédéric and Sophie, 2015).

The individuals of the species found change among themselves in the different parameters studied as well as in the behavior. During the field surveys in the hottest days, we noticed the presence especially of the bapisana species, on the other hand,Otalapunctata was scattered on the ground with completely empty shells, which leads us to say that thebapisana may be the most resistant species among those studied. The presence of the majority of species at El Tarf may be due to the geographical position, effectively this part of Algeria it's the most humid and be part of humid climate stage. . Also that the socio-cultural state of the citizens of El Tarf is different compared to the other districts visited, they are not interested in snails nor for national marketing or self-consumption which explains the presence of several species. During an investigation in Algiers, exact in the forest of Bouchaoui, it was noted that there were 14 species of snails in this forest, but lately, the number of species to decrease until4 species only because of illegal collection. In general, land snails in Algeria are endangered due to illegal pickup, black marketing and pollution (BouchibaandMetahri 2020).

\section{Conclusion}

Based on the results of our study and given the importance of snails in the field of agriculture our study offering an important document for improveheliciculture in Algeria witch it is the first one in the field. Therefore, it is necessary to evaluate and enhance our genetic resources by relying on morphometric and phenotypic characterizations in order to identify the different local species. From the results obtained by this work, we can see that the Algerian land snail population exhibits a great polymorphism given the diversity of shells and flesh color, the morphological and phenotypic heterogeneity of which is very remarkable. We hope do in the near future genetic characterization for a best identification and reasonable economic exploitation.

\section{References}

Amina A 2016. Impact de la pollution industrielle (métauxlourds) sur le développement et la reproduction de l'escargot Helixaspersa : effet sur les bio marqueurs.

Bouchiba I. and Metahr R 2020. Caractérisation morphométrique et phénotypique des escargots terrestres en Algérie. Mémoire de master en génétique, université de Tlemcen. P 107.

Cortet J 2010.Biodiversité des microarthropodes du sol en agroécosystèmes. Mémoire présenté en vue de l'obtention du diplôme d'Habilitation à Diriger des Recherches (HDR). Institut National Polytechnique de Lorrain. P 142

Dallinger R. Berger B. Triebskorn-Köhler R. Köhler H 2001. Soil ecology and ecotoxicology, p. 489-525. In G.M. Barker (ed.), The Biology of Terrestrial mollusks. Cab International, Oxford, England

Damerdji A. 1990. Contribution à l'Etude Biosystématiquedes Mollusques Gastéropodes PulmonésTerrestres de la Région de Tlemcen, Thèse de Magister, Université de Tlemcen. Pp 256

DeVaufleury A. Fritsch C. Gimbert F. Pauget B. Courdassier M. Crini N. Scheifler R 2009.Utilisation etintérêts des escargots etdesmicromammifères pour la bioindicationde la qualitédes sols. ÉtudeetGestion des Sols, 16(34): 203- 217

Frédéric M. and Sophie M. 2012. Escargots synanthropiques et domestication de la nature », Techniques \& Culture, 59: 260-283.

Gomot L. Gomot S. Boukras A. Bruckert S. 1989. Influence of soil on the growth of the land snail Helix aspersa: An experimental study of the absorption route for the stimulating factors. J. Moll. Stud. 55:1-7

Gomot-de Vaufleury A. Pihan F. 2000. Growing snails used as sentinelsto evaluate terrestrial environment contamination by trace elements.Chemosphere, $40: 275-284$

Grall J. Coic N. 2006. Synthèse des méthodes d'évaluation de la qualité du benthos en milieu cotier,p13

Gray J. S. McIntyre A. D. Stirn J. 1992. Manuel des méthodes de recherchesurl'environnementaquatique. Onzièmepartie. Evaluation biologique de la pollution marine, euégardenparticulier au benthos. FAO Document technique sur les pêches, $\mathrm{N}^{\circ} 324,53$

Labaune C. Magnin F. 2001. «Land snail communities in Mediterranean upland grasslands: the relative importance of four sets of environmental and spatial variables », Journal of Molluscan Studies, 67: 463-474.

Rasband W. S. 2014. ImageJ, U. S. National Institutes of Health, Bethesda, Maryland, USA, http://imagej.nih.gov/ij/, 1997-2014+

Zaafour M. 2014. Étude écophysiologiquede la reproduction de l'escargot terrestrePetit-Gris (Helixaspersaaspersa, Gastropoda:Stylommatophora;Helicidea) dans la région Nord-Est d'Annaba - Algérie. Thèse de doctorat, Universite de ANNABA, pp 125. 